\title{
The Importance of Family Education to Instill Children's Moral Character in The Era Of Industrial Revolution 4.0
}

\author{
Vena Nur Litasari, Ratna Handayani Pramukti, Nur Alfi Farikhah, Ratna Hidayah \\ Universitas Sebelas Maret \\ venanurlitasari25@gmail.com
}

\section{Article History}

accepted 24/09/2019

\begin{abstract}
Family education is a means of forming the most basic moral character of children. However, in the present era of gadget addiction in children is increased due to lack of attention and parental supervision as well as the failure of the elderly in his distortions. Causing the child to not control a good life pattern. The purpose of this study. To provide an expansion of knowledge and understanding for parents to be able to apply family education. The negative impact on the child one of them makes the child less sensitive to the homework, and addicted to playing gadgets because of the time they are utilizing by playing games. So it is necessary to expand the knowledge and understanding of family education in the hopes that parents can perform their role well through effective parenting patterns to form the values of good children's moral character
\end{abstract}

Keywords: education, family, child characters

\section{Abstrak}

Pendidikan keluarga merupakan sarana pembentukan karakter moral anak yang paling dasar. Namun, di era sekarang kecanduan gadget pada anak-anak meningkat karena kurangnya perhatian dan pengawasan orang tua serta kegagalan orang tua dalam mendidiknya. Menyebabkan anak tidak dapat mengontrol pola hidup yang baik. Tujuan dari kajian ini

Untuk memberikan perluasan pengetahuan dan pemahaman bagi orang tua agar dapat menerapkan pendidikan keluarga. Dampak negatif yang ditimbulkan pada anak salah satunya menjadikan anak kurang peka terhadap pekerjaan rumah, dan kecanduan bermain gadget sebab waktu yang ada mereka memanfaatkan dengan bermain game. Sehingga diperlukan adanya perluasan pengetahuan dan pemahaman tentang pendidikan keluarga dengan harapan orang tua dapat melakukan perannya dengan baik melalui pola pengasuhan yang efektif untuk membentuk nilai- nilai karakter moral anak yang baik.

Kata kunci: pendidikan, keluarga, karakter anak

Social, Humanities, and Education Studies (SHEs): Conference Series https://jurnal.uns.ac.id/shes

p-ISSN 2620-9284

e-ISSN 2620-9292 


\section{PENDAHULUAN}

Di tengah-tengah peradaban dunia yang serba modern, manusia semakin gencar beralih ke teknologi yang semakin canggih. Pengaruh besar yang ditimbulkan dari adanya kemajuan teknologi, tentu dirasakan oleh seluruh masyarakat di segala penjuru dunia. Persebaran informasi yang begitu cepat tersampaikan hanya melalui perangkat yang berbasis teknologi canggih. Perkembangan teknologi modern membawa dampak perubahan sosial yang begitu cepat sehingga mengubah sendi kehidupan manusia. Tak terkecuali nilai-nilai sosial yang kian menurun seiring perkembangan zaman, menimbulkan dampak bagi manusia. Terlebih anak-anak rentan terpengaruh adanya perkembangan teknologi.

Kegagalan peran keluarga dalam mendidik anggota keluarga di masa revolusi industri 4.0 seperti kurangnya wawasan dan kesadaran keluarga dalam mendidik anggota keluarga sehingga anak diberi kebebasan untuk bermain dengan dunianya seiring perkembangan teknologi digital. Tidak banyak orang tua yang mampu melebihi kepintaran anak dalam menguasai teknologi digital. Ditambah lagi dengan kurangnya monitoring atau pengawasan orang tua dalam membebaskan anak menggunakan teknologi digital.

Fakta membuktikan penelitian yang dilakukan oleh UNICEF bersama Kementerian Komunikasi dan Informatika menerangkan, bahwa 30 juta anak dan remaja Indonesia merupakan pengguna aktif gadget. Mereka menghabiskan waktu selama lima jam sehari untuk gadget. Selajutnya, Indonesia Hottest Insight juga melakukan survei, hasilnya menunjukkan bahwa, 40\% anak Indonesia sudah terampil dalam memanfaatkan teknologi digital. Secara detail menunjukkan bahwa, $63 \%$ anak telah mempunyai akun FB, untuk mengupdate status dan mengunggah foto - foto selfinya. Terdapat $9 \%$ anak telah mempunyai akun Twitter, dan $19 \%$ anak bermain game online di internet dari gadget-nya. (Koran Jakarta, 2019). Berdasarkan hal tersebut, dapat diartikan anak zaman sekarang sudah banyak yang kurang mendapat kasih sayang dan pengawasan dari keluarga dalam menggunakan gadget.

Orang tua merupakan pendidik pertama yang membekali anak dengan menanamkan karakter, sikap, dan perilaku hendaknya mampu mengawasi perkembangan anak. Sejauh mana anak berinteraksi dengan dunianya. Keluarga juga dijadikan sebagai awal pembentukan karakter dari seseorang anak yang nantinya akan memberrikan pengamalan yang baik.

Keluarga diartikan sebagai sebuah institusi paling penting dalam mewujudkan pendidikan dasar dan progres perkembangan anak. Penentuan pola pikir, karakter dan sifat alami dari seseorang anak bisa didapatkkan dari pengalaman anak itu sendiri (Ganevi, Tanpa Tahun).

Oleh karena itu, keluarga harus dapat menanamkan pengalaman yang dapat meningkatkan pengetahuan dan kepribadian anak yang baik. Mengingat di era sekarang menjajaki era revolusi industri 4.0, generasi zaman sekarang selain dihadapkan dengan peluang, tetapi juga tantangan.

Terlebih di zaman ini revolusi industri 4.0, semua orang dimudahkan dalam mendapatkan informasi yang menyebar dengan begitu cepat melalui teknologi digital yang kiancanggih. Pengaruh positif adanya Revolusi Industri 4.0 terhadap pendidikan keluarga dapat menyebabkan pergeseran sikap dan nilai anggota keluarga yang awalnya tidak memiliki landasan kini berlandaskan pada nilai moral. Sedangkan pengaruh negatif adanya Revolusi Industri 4.0 terhadap pendidikan keluarga yakni teknologi maju dapat memudahkan anggota keluarga sehingga mereka beranggapan bahwa mereka tidak lagi membutuhkan bantuan orang lain dalam memenuhi kehidupan,bahkan mereka kadang luput bahwa diri mereka merupakan makhluk social sehingga perlu berinteraksi dengan sesamanya, sehingga intensitas interaksi antar anggota keluarga berkurang (Zahra dkk, 2019: 129). 
Pendidikan keluarga memiliki urgensi yang sangat penting dalam mempersiapkan nilai moral yang akan ditanamkan bagi keberlangsungan tumbuh kembang anak yang menjadi penopang untuk pendidikan di masa mendatang (Mansur, 2005). Dengan adanya pemahaman tentang pendidikan keluarga diharapkan orang tua dapat melakukan perannyadenganbaikmelauipolapengasuhan yang efektifuntukmembentuknilai- nilaikarakter moral anak yang baik.

Berdasarkan uraian di atas, masalah ini memfokuskan pada dampak yang ditimbulkan akibat kurangnya pendidikan keluarga dalam mendidik anak dan bagaimana solusi untuk mengatasi masalah dalam mendidik anak ditengah era revolusi industri 4.0. Harapannya ini dapat menjadi referensi bagi para orang tua dalam menerapkan pendidikan keluarga untuk menanamkan karakter moral anak ditengah era digital.

\section{A. Pendidikan Keluarga}

\section{HASIL DAN PEMBAHASAN}

Pendidikan keluarga adalah segala macam upaya yang dilakukan oleh orang tua dengan membiasakan anak untuk melakukan perilaku / hal yang baik dan melakukan improvisasi dalam melihat dan mendampingi perkembangan pribadi anak (Achad Hufad: Tanpa Tahun). Pada kenyataannya pendidikan keluarga saat ini tidak terlalu memikirkan perkembangan pribadi anak, sehingga anak diberikan kebebasan untuk berperilaku semaunya sendiri. Padahal Keluarga merupakan sebuah tempat pendidikan utama, namun peran pendidikannya tidak terlalu diperhatikan. Ki Hajar Dewantara (1961) dalam Jurnal Pendidikan Islam (2014) berpendapat bahwa keluarga memiliki alam, yaitu alam keluarga. Alam keluarga setiap anak yaitu permulaan alam pendidikan. Orang tua berperan sebagai guru yang utama bagi anak-anaknya yang memiliki peran sebagai pendidik, pembimbing, dan pengajar. Oleh sebab itu, orang tua berkewajiban mendidik anaknya untuk memiliki kepribadian moral yang baik agar di masa depan nanti sudah memiliki landasan yang kokoh dan baik. Menurut Suardi (2016) untuk mengantisipasi pengaruh luar di masa mendatang, diperlukan pembiasan sikap karena nantinya anak akan menjajaki kehidupan di masa mendatang.

\section{B. Manfaat Pendidikan Keluarga}

Pendidikan keluarga memiliki maanfat yang sangat besar untuk keberlangsungan hidupnya dimasa depan. Menurut Fuad Insan (1997) Jurnal IImiah DIDAKTIKA (2012) mengenai manfaat dengan adanya tanggung jawab kedua orang tua dalam pendidikan keluarga sebagai berikut:

1. Membesarkan dan memilihara anak, merupakan ini sifat alami yang harus dilaksanakan karena anak memiliki kebutuhan primer yang harus dipenuhi.

2. Memberikan perlindungan dan memberikan jaminan kesehatan. Kesehatan jasmani dan rohani dari segala gangguan dari lingkungan.

3. Mendidik anak dengan memberikan pendidikan formal maupun nonformal dan keterampilan, sehingga ketika anak tumbuh dewasa dapat memberikan manfaat bagi orang lain.

4. Memberikan kebahagian bagi anak, melalui pendidikan religi sesuai ajaran agama yang dianutnya.

\section{Pendidikan Karakter}

Pendidikan karakter di lingkungan keluarga adalah sesuatu yang sangat penting dalam perkembangan anak. Pendidikan karakter menurut John Dewey (Maemonah, TanpaTahun) merupakan misi utama dan aspek utama dari pendidikan karakter adalah moralitas atau pendidikan moral. Moral dapat diklasifikasikan menjadi tiga, antara lain: moral sebagai ajaran kesusilaan, tuntutan berperilaku yang sesuai dengan aturan dalam moral yang baik dan meninggalkan moral yang buruk yang dinilai menyimpang 
dengan norma yang berlaku dilingkungan sekitar; moral dijadikan landasan aturan, ketentuan yang sudah ditetapkan menjadi acuan sebagai suatu aturan yang dipergunakan untuk menyeleksi perilaku seseorang baik atau buruk; moral sebagai tanda-tanda kejiwaan seseorang yang berwujud perilaku, sebagai contoh jujur, bertanggung jawab, gairah, berani, dan lain sebagainya.

Moral yang dikembangkan melalui pendidikan karakter melahirkan sikap yang didasarkan pada aturan moral yang sudah dibentuk oleh kesadaran yang berjenjang. Mulai dari pengetahuan tentang moral, perasaan tentang moral sampai tindakan moral. (Lickona, 1991: 53)

\section{Dampak Revolusi Industri 4.0 \\ 1. Dampak Positif}

Dampak positif dari munculnya Revolusi Industri 4.0 terhadap pendidikan keluarga menyebabkan adanya perubahan nilai dan sikap anggota keluarga.

Di sector ekonomi telah terlihat banyak barang melimpah dan harga murah, perdagangan yang makin berkembang, transportasi makin lancar. Di bidang social yaitu interaksi social menjadi tak terbatas dengan adanya akses internet dan teknologi.

Di bidang politik terlihat kemudahan akses digital dan aksi politik kini dapat diakses melalui media social dengan mengusung ideology politik tertentu. Terbukti sekarang banyak muncul gerakan sosialis dan partai politik. (Prasetyo, B danTrisyanti, $U: 22)$

\section{Dampak Yang Negatif}

Dampak negative adanya Revolusi Industri 4.0 terhadap pendidikan keluarga adalah anggota keluarga dimudahkan melalui kemajuan teknologi sehingga merasa tidak lagi membutuhkan orang lain dalam beraktivitas, kadang melupakan dirinya sebagai makhluk sosial yang perlu berinteraksi dengan sesamanya, sehingga intensitas interaksi antar anggota keluarga berkurang (Zahra dkk, 2019: 129).

Di sector ekonomi dapat terlihat sebuah ancaman kurangnya lapangan pekerjaan yang menjadikan pengguna akibat otomatisasi, kerusakan alam akibat ekspoitasi industri, perusahaan kecil gulung tikar karena munculnya golongan pengusaha serta maraknya hoax akibat mudahnya penyebaran informasi.

\section{E. Implikasi Pendidikan Keluarga di Era Revolusi Industri 4.0 terhadap Karakter Moral Anak}

Dalam pendidikan keluarga sangat penting untuk menanamkan karakter anak dalam tantangan di era revolusi industri 4.0, orang tua perlu memberikan teladan berupa sikap atau perilaku yang patut untuk dicontoh yang mengandung nilai-nilai karakter, seperti sifat jujur, benar, ikhlas, adil, dan nilai-nilai karakterlainnya. Dengan harapan ketika mengahadapi tantangan di era revolusi industry 4.0, anak menjadi terbiasa bersikap dan berperilaku demikian. Pengetahuan serta pemahaman keluarga dalam mengasuh anak berdampak dalam perkembangan dan masa depan anak. oleh karena itu, setiap keluarga perlu di beri sebuah keterampilan dan pengetahuan dalam mengasuh serta membimbing anak agar dapat menjadi manusia yang bermutu di masa depan.(Ganevi, TanpaTahun).Melalui hal tersebut, program parenting adalah salah satu tempat yang dapat digunakan dalam membangun kualitas orangtua seperti penanaman sikap ramah anak.(Ganevi, TanpaTahun).

Pentingnya pendidikan keluarga di era Revolusi Industri 4.0 yaitu mengarahkan anak-anaknya agar mampu menghadapi banyaknya tuntutan serta menanamkan nilai dan sikap pada anak. Nilai dan sikap yang ditanamkan pada anak diketahui 
dalamsikap orangtua sebagai contoh di depan anak (Akhyadi, 2018). Dengan adanya penanaman nilai dan moral diharapkan anak mampu terbiasa dengan sifat-sifat yang baik serta mendorong anak untuk memiliki kemampuan berfikir tinggi. Ketika anak mempunyai kemampuan berfikir tingkat tinggi, diharapkan anak dapat bersaing dengan kompetitif dan menciptakan inovasi serta kreativitas yang dimiliki untuk menyelesaikan tantangan yang dihadapi.(Ormrod, 2008).

\section{SIMPULAN}

Keluarga merupakan sebuah tempat pendidikan utama, namun peran pendidikannya tidak terlalu diperhatikan. Pendidikan keluarga memiliki maanfat yang sangat besar untuk keberlangsungan hidupnya dimasa depan. Pendidikan karakter dalam lingkungan keluarga adalah yang utama dalam perkembangan anak karena pendidikan karakter adalah misi utama dan aspek utama dalam pendidikan karakteradalah moral. Dampak positif dan negative adanya Revolusi Industri 4.0 terhadap pendidikan keluarga dari berbagai aspek seperti aspek sosial, ekonomidanpolitik. Pendidikan keluarga sangat penting karena keluarga dapat mengarahkan anak-anaknya agar mampu menghadapi banyaknya tuntutan serta menanamkan nilai dan sikap pada anak.

\section{DAFTAR PUSTAKA}

Akhyadi, A. S \& Mulyono, D. (2018). Program Parenting Dalam Meningkatkan Kualitas Pendidikan Keluarga, 2 (1), 1-8: Jurnal Pengabdian Kepada Mayarakat (Abdimas). Diunduh dari https://journal.ikipsiliwangi.ac.id/index.php/abdimassiliwangi/article/download/34/3 pada tanggal 08 September 2019.

Baharu, H. (2016). Pendidikan Anak Dalam Keluarga; Telaah Epistemologis, Jurnal Pendidikan, 3 (2), 96-107. Diunduh dari https://ejournal.unuja.ac.id/index.php/pedagogik/article/download/126/106 pada tanggal 08 September 2019

Emzir. (2010). Metodologi Penelitian Pendidikan Kuantitatif dan Kualitatif. Jakarta: Rajawali Pers.

Ganevi, N. (Tanpa Tahun). Pelaksanaan Program Parenting Bagi Orang Tua Dalam Menumbuhkan Perilaku Keluarga Ramah Anak (Studi Deskriptif di Pendidikan Anak Usia Dini Al-Ikhlas Kota Bandung). HIm 2. Departemen Pendidikan Luar Sekolah, Fakultas Ilmu Pendidikan, Universitas Pendidikan Indonesia.

Hufad, A. (Tanpa Tahun). Keluarga dan Pendidikan Anak (Tinjauan Sosiologi Agama terhadap Proses Pendidikan Anak dalam Keluarga). Artilel Keluarga dan Pendidikan Anak. Diunduh dari http://file.upi.direktori.FIPPDF

Jailani, M. S. (2014). Teori Pendidikan Keluarga dan Tanggung Jawab Orang Tua dalam Pendidikan Anak Usia Dini. Jurnal Pendidikan Islam Vol. 8, Nomor 2, Oktober 2014. IAIN Sulthan Thaha Saifuddin Jambi.

Kementerian Pendidikan dan Kebudayaan Republik Indonesia. (2016). Seri Pendidikan Orang Tua:Mendidik Anak di Era Digital, Cet. I. Jakarta:Kementerian Pendidikan dan Kebudayaan.

Koran Jakarta. Mendidik Anak di Era 4.0. Diunduh dari http://www.koranjakarta.com/mendidik-anak-di-era-4-0/

Lickona, Thomas. 1991. Educating for Character. New York: Bantam Book.

Maemonah. (Tanpa Tahun). Aspek-aspek dalam Pendidikan Karakter. Jurusan Tarbiyah Sekolah Tinggi Agama Islam Negeri (STAIN) Pekalongan. Diunduh dari http://media.neliti.com pada 29 September 2019.

Mansur. (2005). Pendidikan Anak Usia Dini Dalam Islam, Yogyakarta: Pustaka Belajar.

Ormrod, J. E. (2008). Psikologi Pendidikan (Membangun Siswa Tumbuh dan Berkembang), Edisi 6, Jilid I. Jakarta: Erlangga. 
Prasetyo, B dan Trisyanti, U. (Tanpa tahun). Revolusi Industri 4.0 dan Tantangan Perubahan Sosial. Institut Teknologi Sepuluh Nopember. Diunduh dari http://iptek.its.ac.id/index.php/jps/article/download/4417/3156 pada tanggal 29 September 2019.

Rahmat, S. T. (2018). Pola Asuh Yang Efektif untuk Mendidik Anak di Era Digital. Jurnal Pendidikan dan Kebudayaan Missio. Volume 10, Nomor 2, Juni 2018, hlm. 144. Program Studi Pendidikan Guru PAUD STKIP Santu Paulus Ruteng.

Rakhmawati, I. (2015). Peran Keluarga Dalam Pengasuhan Anak, 6 (1) , 1-18. Jurnal Bimbingan Konseling Islam. Diunduh dari http://journal.stainkudus.ac.id/index.php/konseling/article/viewFile/1037/949 pada 4 September 2019.

Suardi. (2016). Pendidikan IImu-IImu Sosial Membentuk Karakter Bangsa Dalam Rangka Daya Saing Global. Universitas Negeri Makassar.

Wahy, H. (2012). Keluarga Sebagai Basis Pendidikan Pertama Dan Utama, Jurnal IImiah DIDAKTIKA, 12(2), 245-258. Diunduh dari https://jurnal.arraniry.ac.id/index.php/didaktika/article/download/451/362 pada tanggal 08 September 2019

Zahra, A.C. dkk. (2019). Peran Pendidikan Keluarga dalam Menghadapi Tantangan Revolusi Industri 4.0. (2019) Prosiding Seminar Nasional \& Call Paper Psikologi Pendidikan. Fakultas Pendidikan Psikologi, Aula C1, 13 April 2019. HIm 129. Program Studi Psikologi, Fakultas Pendidikan Psikologi, Universitas Negeri Malang.

Zakaria, Teuku Ramli. (2010). "Pendekatan-pendekatan Pendidikan Nilai dan Implementasi Pendidikan Budi Pekerti". Diunduh dari http://pdk.go.id/balitbang/publikasi/jurnal pada 29 September 2019. 